\title{
Place-based modelling of social vulnerability to COVID-19 in Nigeria
}

\author{
Olanrewaju Lawal ${ }^{1} \cdot$ Tolulope Osayomi $^{2}$ (])
}

Received: 20 July 2020 / Accepted: 21 October 2021 / Published online: 22 November 2021

(c) The Author(s), under exclusive licence to Springer Nature Switzerland AG 2021

\begin{abstract}
COVID-19, within a short period of time, grew into a pandemic. The timely identification of places and populations at great risk of COVID-19 infection would aid disease control. In Nigeria, where a variety of recommended and adopted nonpharmaceutical interventions seem to have limited effectiveness, the number of cases is still increasing. To this end, this paper computed a social vulnerability to COVID-19 index (SoVI) in Nigeria within the local government area (LGA) framework with a view to revealing vulnerable places and populations. The study relied on several data sources and factor analysis for the development of the index. SoVI values ranged from 2.3 (least vulnerable) to 6.8 (most vulnerable). Three percent of the 774 LGAs were extremely vulnerable while $2 \%$ of these LGAs were least vulnerable to COVID-19. The predictive power of the index was confirmed to be strong $(r=0.812)$. Hopefully, the visual representation of place-based vulnerability to COVID-19 index should guide and direct the relevant authorities in the containment of further spread and vaccination coverage.
\end{abstract}

Keywords COVID-19 · Pandemic · GIS · Social vulnerability $\cdot$ Nigeria

\section{Introduction}

The world woke up to the news of the outbreak of a newly emerging viral infection later known as COVID-19 in the city of Wuhan, Hubei province, People's Republic of China in December 2019. The World Health Organisation (WHO) initially declared the outbreak a public health emergency of international concern and later on upgraded to a pandemic, following its rapid diffusion to over 200 countries within four months of its outbreak. Currently, the number of global

Tolulope Osayomi

osayomi@yahoo.com

1 Spatial Data Science Group, Department of Geography and Environmental Management, Faculty of Social Sciences, University of Port Harcourt, Port Harcourt, Nigeria

2 COVID-19 Mapping Lab, Department of Geography, University of Ibadan, Ibadan, Nigeria 
COVID-19 cases have surpassed 210 million while deaths arising from these cases are over 4.5 million. Nothing of this kind has never been seen in recent history. It is in fact unlike, the previous outbreak of Severe Acute Respiratory Syndrome (SARS) of 2003 and Ebola in West Africa of 2014. Clearly, the spread and the impact so far, have clearly highlighted the importance of data and disease surveillance in managing health emergencies and disasters. It is based on this understanding that the study developed a COVID-19-specific social vulnerability index (SoVI) aimed at supporting ongoing efforts in Nigeria against the pandemic. This study specifically proposes a SoVI for the rapid mapping of COVID-19 at the microscale particularly in countries with huge data gaps.

No doubt, this outbreak of COVID-19 is an issue of global concern. However, more worrisome is that as the disease spreads further, it becomes particularly detrimental to specific vulnerable social groups such as those living in poverty, elderly persons, those with one form of disability or pre-existing medical conditions, the youth and indigenous people (United Nations 2020). In addition, the exposure to this disease will be further worsened by the existing inequalities in the society particularly due to the differential access to the societal resources such as medical care, water, sanitation and hygiene facilities.

Hazards usually precede disasters, however, not all hazards end up in disaster. Thus, we are all always exposed, but our response and preparation will determine whether such will result in disaster. The management of disasters requires understanding of risks, hazards, vulnerability and resources to minimize the effect hazards. In essence, it is common to see relationship such as "Risk $=$ Hazard * vulnerability", but there are a number of other conceptualisations e.g. Risk= hazard * [vulnerability - resources] (Flanagan et al. 2011). In these instances, risk is referred to as the likelihood of loss; hazard as a condition that is likely to cause harm; vulnerability as the extent to which persons or things are likely to be affected; while resources are assets in place that will mitigate the effects of the disaster or hazard event.

A close look at the vulnerability component of the risk equations stated earlier reveals that this potential for loss (life or property) could be a characteristic of places and people. As such vulnerability could be as a result of biophysical or social attributes (Cutter 1996). When the vulnerability is conferred by the attributes of the hazard event or the physical condition of the place, this relate to biophysical vulnerability. On the other hand, when the vulnerability is conferred by the attributes of the people and the society at large which could impact negatively on the outcome of a hazard event or disaster, this relates to social vulnerability (SoVI) (Lawal and Arokoyu 2015).

In spite of increasing attention given to disaster management across developing countries and the establishment of disaster and emergency management agencies in many African countries witnessed a slow progress in the implementation of the Hyogo Framework for Action 2005-2015 (Manyena 2016). Thus, highlighting the challenges faced by a region in the implementation of the subsequent Sendai Framework for Disaster Risk Reduction. There is a growing body of work on quantification and mapping of social vulnerability and resilience in 
low and middle income countries (Ran et al. 2020) all geared towards supporting disaster risk management. This is an indication that capacity and understanding is growing.

Biophysical vulnerability is usually on the front burner for the national emergency management agency in Nigeria. This could be because flood is the most recurring natural hazard in Nigeria. It could also be due to the fact that SoVI is, partly, socially constructed thus, dependent on many factors endogenous to individuals and groups thus making it very difficult to track (subjective) (Béné et al. 2016). However, there is a need to create a framework to assess SoVI at a national regional and local scale, whereby an assessment and data collection at the local level can feed into the regional and national dataset for planning and policy making at each respective level. However, in the absence of such, there is need to use available data to create a model of relative SoVI which could support evaluation of resource preposition for the current COVID-19 pandemic.

Essentially, understanding of how the current pandemic will affect people is critically important. Equally important is where the vulnerable people and places are. Such understanding could improve allocation of resources in health emergencies such as this COVID-19 pandemic and disaster management in the future, thus ensuring that people stay safe and do not further exacerbate the pandemic in Nigeria. This study, therefore, modelled SoVI to COVID-19 at the Local Government Area (LGA) level using available data with the aim of creating a relative index to support mitigation efforts and vaccination campaigns against the COVID-19 pandemic.

\section{Data and methods}

\section{Study area}

Nigeria is the most populous in Africa, with a population of over 200 million (Population Reference Bureau 2021), which accounts for more than $47 \%$ of the total population of West Africa (The World Bank Group 2015; The World Bank Group 2016a). Its population density is over 151 persons per square kilometre (Fig. 1). The country also has a wide ethnic diversity often reported as over 250 groups (Central Intelligence Agency 2015). This often creates a point of tension leading to conflicts and discord-a situation in which an ethnic group could complain of marginalisation or neglect. The population growth rate peaked in the 1970 s and has been stable since then when compared to the regional average (Sub-Saharan Africa) of about $2.73 \%$. Nigeria's population growth rate has been below this average since 1980 and currently stood at $2.63 \%$ per annum (The World Bank Group 2016a).

Recent data from the World Development Indicators (The World Bank Group $2016 \mathrm{~b}$ ) shows that about $46 \%$ of the population live below the national poverty line while $49 \%$ of the rural population has access to improved water sources. The country has an average life expectancy at birth of 52.7 years, which is below the region's average of 56 years. Gross national income per capita has also witnessed a steady increase over the years and currently stands at $\$ 2,820$. In terms of gross domestic 


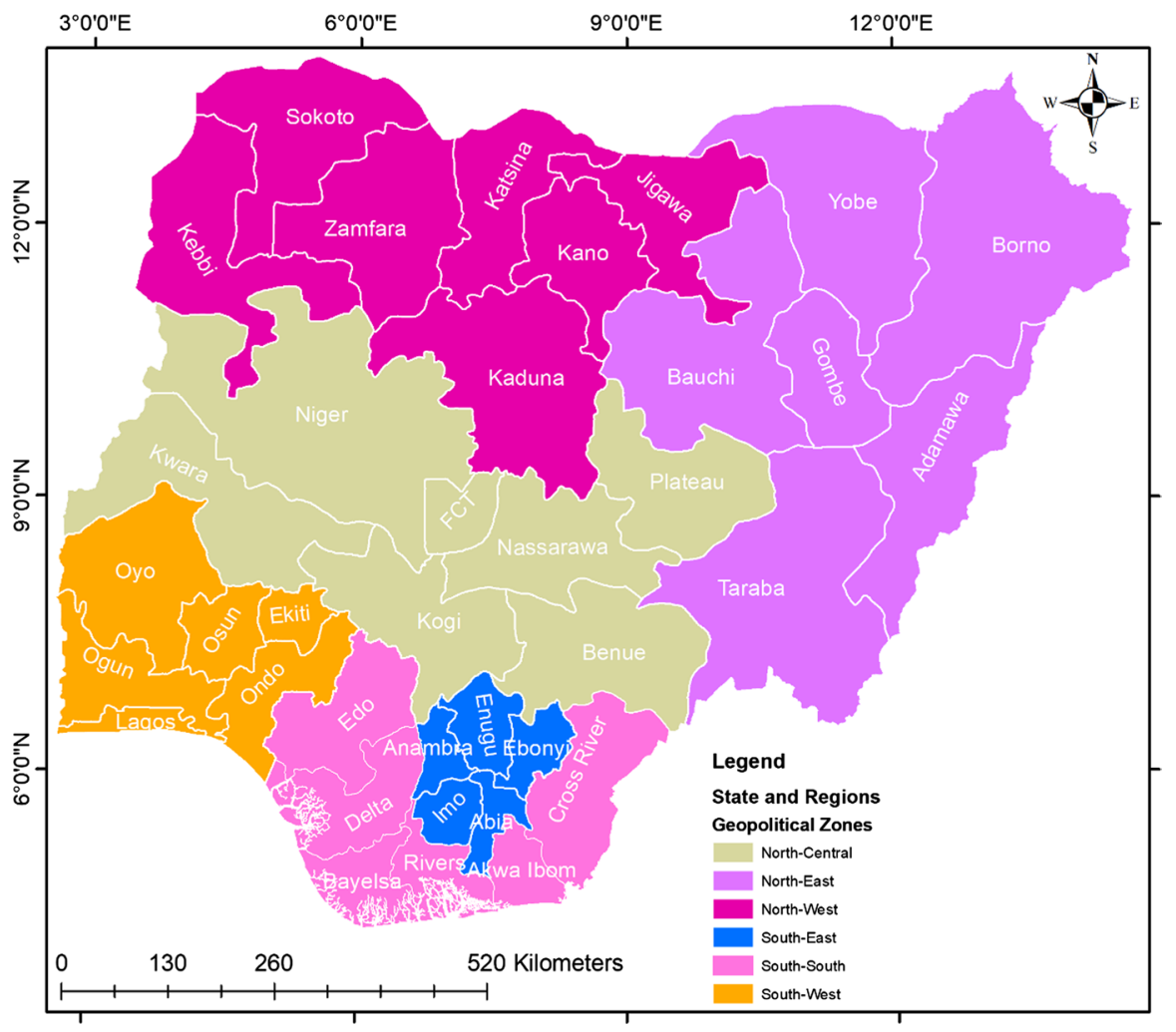

Fig. 1 Population density of states in Nigeria

product (GDP), however, there was a sharp decline from $\$ 568.5$ billion in 2014 to \$481.1 billion in 2015 (The World Bank Group 2016b).

Nigeria is a federation of 36 states and the Federal Capital Territory (FCT). These States are grouped into 6 Geopolitical Zones-South-West, South-South, SouthEast, North-East, North Central and North West (Fig. 2). There are 774 LGA (second level subdivisions) spread over an area of 923,768 square kilometres and about $13,000 \mathrm{Km}^{2}$ of water.

\section{Data}

The study modified the method implemented by Lawal and Arokoyu (2015) to create an index of social vulnerability (SoVI) to COVID-19, thus, quantifying the relative vulnerability of a place based on socioeconomic variables. This study constructed the SoVI using data as enumerated in Table 1. Subsequent statement highlights the justification for the choice of variables.

The proportion of the elderly population is a component of this domain capturing the household composition. Older people are said to be the most susceptible 


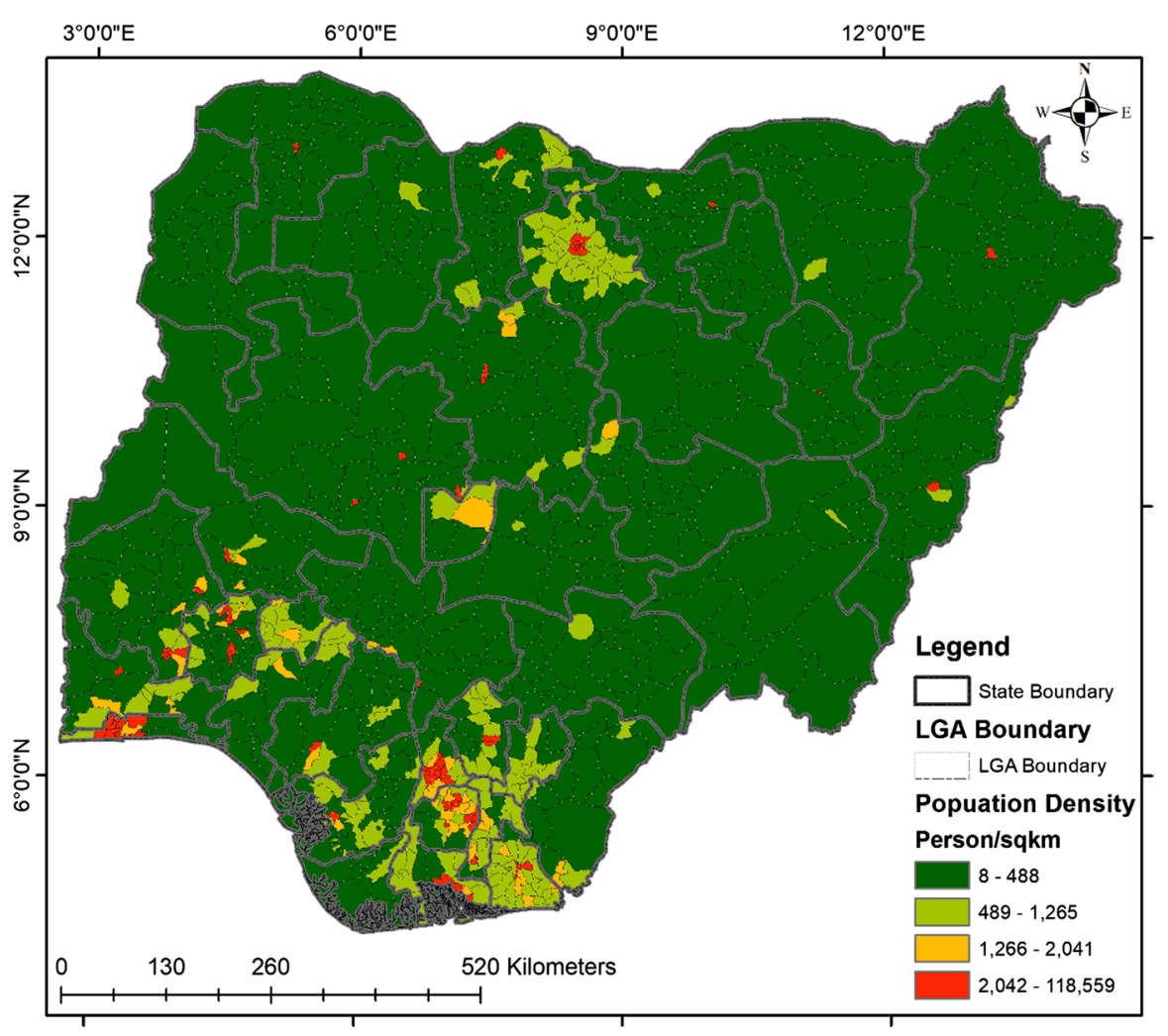

Fig. 2 States and geopolitical zones in Nigeria

to COVID-19 particularly those with pre-existing health conditions such as cardiovascular diseases, diabetes, cancer, respiratory infections etc. (Li et al. 2020). As a matter of fact, a large proportion of deaths are from the elderly (Ioannidis et al. 2020). In addition, the elderly population are generally susceptible to illness because of the decline in their immunity system on account of old age.

The distribution of healthcare facilities, level of urbanisation, population density, level of economic activities and the presence of airports captures different dimensions of development, population, economy and spatial interaction. All these have mixed effects on the degree of vulnerability to COVID-19. It could either increase or reduce the population's vulnerability to infection. The availability of healthcare facilities would reduce vulnerability to COVID-19. The level of urbanisation and population density facilitates the spread of infectious diseases. Infectious diseases diffuse faster if the size of population is large and densely concentrated in geographic areas. This is confirmed in the United States of America where COVID-19 infection rates increased with city size (Stier et al. 2020), Nigeria (Olusola et al 2020; Okafor and Osayomi 2021, West Africa (Osayomi et al 2021a). 


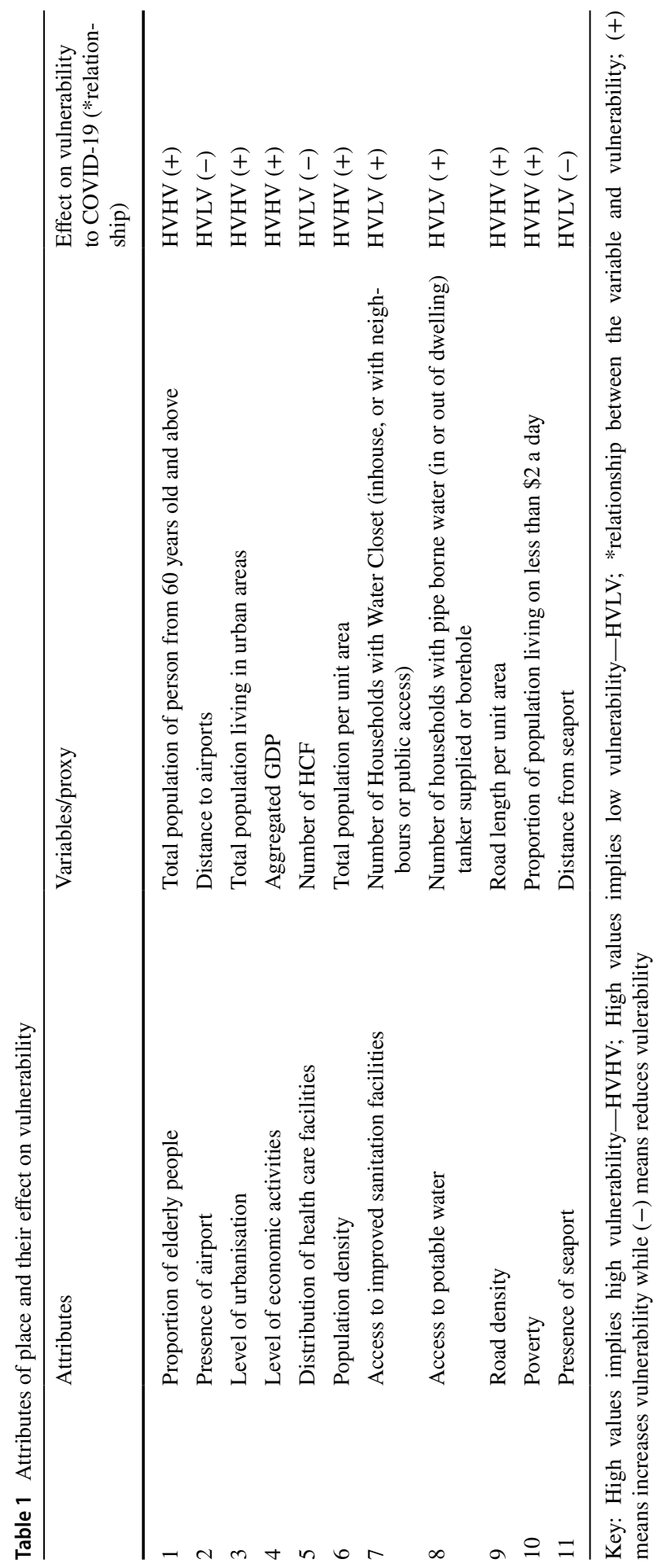


Human mobility facilitates infectious disease transmission. With respect to COVID-19, its rapid diffusion has been attributed to domestic and international travel within China and the outside world. For instance, domestic and international travellers from Wuhan, China facilitated the spread particularly during the annual Lunar New Year celebrations. With travel restrictions in place, it effectively slowed down the spread in the early days of the outbreak (Chinazzi et al. 2020; Kraemer et al. 2020). In Africa, international travel strongly influenced the spatial pattern of COVID-9 prevalence (Onafeso et al 2021; Osayomi et al. 2021a,b).

Also vulnerable to COVID-19 are the indigent people, who before the outbreak of the disease, had been experiencing limited access to healthcare, higher rates of communicable and non-communicable diseases, poor access to essential services, poor sanitation, and other preventive measures, such as clean water, soap disinfectant, among others (United Nations 2020). This is further reiterated by UNICEF (2020) that $40 \%$ of the world's population which is about 3 billion people do not have handwashing facility with water and soap at home, with about three quarters of the people in least developed countries lacking basic handwashing facilities at home. Likewise, most local medical facilities are usually ill equipped and understaffed. They also face stigma and discrimination when accessing healthcare services (United Nations 2020).

Proportion of elderly people was computed from the gridded $(100 \mathrm{~m})$ age structure data from WorldPop (2014). The data is made up of the number of people within each 5-year age group for every $100 \mathrm{~m}$ grid square. In essence, the population for the age group from 60 and above were extracted and utilised for this study. Consequently, an LGA with more elderly people as captured by this dataset will be more vulnerable to the negative impact of COVID-19 if the disease is allowed to spread uncontrollably across the country.

The data about the location of airports in the country across the country were extracted from ESRI (2020). To capture the varying vulnerability across the country in relation to airports (being a potential source of spread of the pandemic), the proximity to the nearest airport was computed. The mean distance from the nearest airports was computed from each State and LGA. Similar procedure was implemented for the location of seaports. The airports and seaports were considered because they are potential sources of spread of the infection and consequently the further away these sources are, the less vulnerable a place is likely to be. The seaport locations were sourced from ESRI (2019).

To capture level of urbanisation, the study utilised the population data obtained from WorldPop (2020). In order to delineate area that could be labelled urban, the population per pixel was classified using the Standard deviation (SD) classification scheme, and based on visual observation and contiguity, cells with more than 6 persons per pixel ( $\geq-0.5 \mathrm{SD}$ ) were classified as urban. Thus, population for these pixels were summed for each LGA and State to give the total at each of these levels of aggregation. Therefore, we hypothesised that the larger the urban population (a proxy for level of urbanisation), the more vulnerable a place is likely to be.

The level of economic activities was captured using the Gross Domestic Product, the dataset used for this was obtained from the work of Lawal and Nuga (2015).. There is a clear indication that places with high level of economic 
activity are disproportionately affected by the disease since they are the major economic hubs such as Lagos (Okafor and Osayomi 2021). Thus, the aggregated GDP for each LGA and State were computed to provide an indication of the level of economic activities.

Health facilities provides a source of capacity to handle the pandemic, as such the presence of such could confer some level of capacity to reduce vulnerability to the negative impact of the pandemic. The location data for the health facilities were downloaded from the Nigeria MDG Information System (2015) OpenAfrica Portal.

The population densitys of the State and the LGAs were included as part of attributes which could increase the level of vulnerability. The aggregation of many people per unit area was computed from the person per pixel datasetWorldPop (2020). The area of each State and LGA was computed (square km) and utilised for computation of population density for each of the spatial entities. The hypothesis therefore is that places with higher population density have relatively high level of vulnerability.

Access to improved sanitation facilities and portable water were included to capture (in) accessibility to Water, Sanitation and Hygiene (WASH) facilities which could either facilitate or control the spread of the diseases generally. The hypothesis here is that lack of these could also be a hindrance for the implementation of frontline mitigation measures, and there is a strong probability for people with inadequate access to be especially vulnerable to other health issues which could weaken their immunity. Thus, inadequate access to potable water and improved sanitation will potentially increase vulnerability. The data for these were extracted from the Priority Tables for the LGAs (National Population Commission 2010). The total number of households with access to water closet, toilet facility in another dwelling, and public toilet were summed up to produce the total number of households with access to improved sanitation facilities. Likewise, the household with access to pipe-borne water inside and outside the dwelling; tanker/water vendor supplied, and borehole water were added up to arrive at the sum total of households with access to potable water. Thus, a higher number of households with access reduces the level of vulnerability to COVID-19.

Road density was computed to represent the volume and ease of movement of goods, people and services. Data for this again was came from the work of Lawal and Arokoyu (2019). The hypothesis is thus that higher road density will more likely fuel the rapid spread of infection in a situation where there is no restriction of movement. Road density were computed for each State and LGA by dividing the total road length by the area of the spatial unit (i.e. state and LGA).

Poverty was also considered. Given its multidimensional nature, we utilised the population living on less than $\$ 2$ a day as an indicator of poverty. This dataset was retrieved from Tatem et al. (2013). Poverty has a negative impact on individual and community preparedness, vulnerability and response to as well as attitude toward disasters or health emergencies. Poverty is an indicator of the lack of access to other amenities, poor standard of living and health outcomes, all of which could suggest a higher prevalence of COVID-19. 


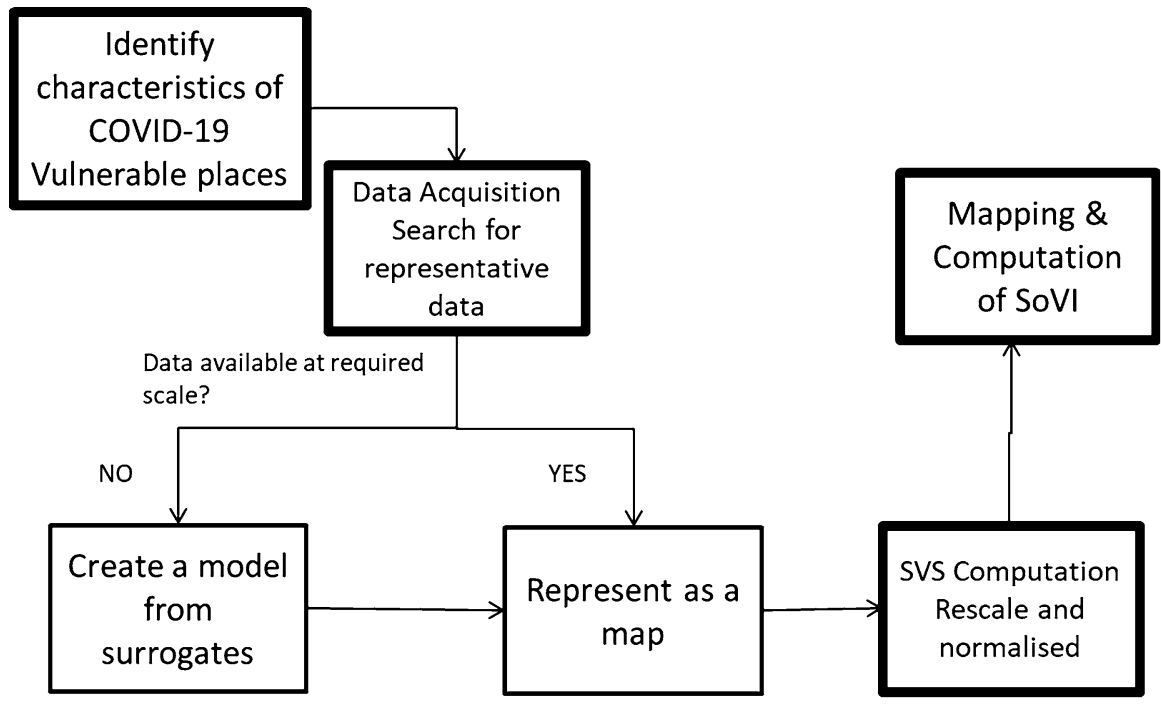

Fig. 3 Steps for modelling place-based vulnerability to COVID-19

\section{Method}

The study adopted the framework illustrated in Fig. 3. The study started with identification of appropriate variables to capture the identified factors from various sources. In a situation where appropriate variables were not available at a particular scale for instance, LGA, a model was used to derive such at that scale. All variables (Table 1) were represented as maps and processed within the GIS environment.

All scores were given equal weight and the sum of all represent the Social Vulnerability Index to COVID-19 infection at the LGA level for Nigeria. This represent the summation of the attributes of the society which could either positively or negatively affect the outcome of COVID-19 pandemic across Nigeria. Thus, a higher index value for this index indicate higher level of vulnerability to COVID-19.

There are two classes of variables: (a) HVHV and (b) HVLV and the Social Vulnerability Scores (SVS) were computed as follows:

For (a) the following steps were followed.

i. Calculate $\mathrm{X}$ value $=\mathrm{LGA}$ value $/$ State value

ii. Calculate $\mathrm{Score}=\mathrm{X}$ value $/$ Maximum of $\mathrm{X}$

For (b) the following steps were executed.

i. Calculate $X$ value $=$ State value - LGA Value

ii. Calculate $\mathrm{Y}$ value $=\mathrm{X}$ value + Maximum of $\mathrm{X}$

iii. Calculate Score $=Y$ value $/$ Maximum of $Y$ 
Places with values close to 1 will be labelled places with high level of vulnerability while those of low vulnerability values are close to zero.

To eliminate redundant variables and identify the dimension with the set of computed SVS, we adopted the approach utilized by Lawal and Arokoyu (2015). They utilized a two-staged feature extraction process combining correlation and factor analysis. For every pair of variables displaying very strong positive correlation $(r \geq 0.9)$ one of them will be dropped. The remaining subset of variables were then subjected to Factor analysis to identify dimensions within the subset and the most important variables (high loading variables).

\section{Results and discussion}

\section{Results}

\section{National distribution of social vulnerability scores}

The descriptive statistics of the SVS (Table 2) shows that scores for distance to airports, seaports, and road density have the highest dispersion across the LGAs. Scores for population density has the lowest mean $(x=0.023, \mathrm{SD}=0.03)$. This indicated that many LGAs, based on the scores, have relatively low population figures and less likely to be vulnerable.

Access to basic amenities (Health care facilities, Improved Sanitation, Potable water) shows relatively high mean values $(0.76,0.59,0.59$ respectively) and minimum values. This gives an indication that many of the LGAs are relatively vulnerable in these aspects.

Proximity to potential sources of infection from outside the country also recorded a relatively high mean score of 0.52 and 0.49 for airports and seaports respectively.

Table 2 Distribution of Social vulnerability scores across Nigeria

\begin{tabular}{llllll}
\hline ID & Variables & Minimum & Maximum & Mean & SD \\
\hline 1 & Score for access to improved sanitation & 0.521 & 1.000 & 0.589 & 0.077 \\
2 & Score for access to potable water & 0.515 & 1.000 & 0.589 & 0.077 \\
3 & Score for proximity to airports & 0.073 & 1.000 & 0.525 & 0.129 \\
4 & Score for proximity to seaports & 0.039 & 1.000 & 0.499 & 0.122 \\
5 & Score for proportion of the elderly & 0.001 & 1.000 & 0.090 & 0.065 \\
6 & Score for intensity of economic activity & 0.001 & 1.000 & 0.091 & 0.065 \\
7 & Score for number of health care facilities & 0.553 & 1.000 & 0.764 & 0.101 \\
8 & Score for population density & 0.000 & 1.000 & 0.023 & 0.069 \\
9 & Score for poverty level & 0.014 & 1.000 & 0.084 & 0.056 \\
10 & Score for density of road (accessibility) & 0.000 & 1.000 & 0.077 & 0.111 \\
11 & Score for size of urban population & 0.000 & 1.000 & 0.068 & 0.091 \\
\hline
\end{tabular}

$N=774$

Source: Authors' computation 
However, there is a high dispersion for these scores, indicating that there is a wide variation for these scores across the LGAs even though a high mean value was recorded.

\section{Association among social vulnerability scores}

The correlation analysis revealed relationship among the scores computed. This was also implemented so as to identify redundant variables. The results (Table 3) show that for SVS for proportion of elderly people and intensity of economic activity are perfectly correlated. Therefore, one of them was dropped in subsequent analysis. Similarly, scores for poverty levels and intensity of economic activity also showed a strong positive correlation. Likewise, access to portable water and improved sanitation were positively correlated. Overall, level of poverty, elderly population and the intensity of economic activity displayed a strong positive relationship. Scores for road density and population density showed a moderate positive correlation. Generally, most of the bivariate correlation coefficients indicated weak associations. This is an indication that each of the scores besides those with perfect correlation coefficients indicated unique dimensions, revealing the components of the society that could affect the spread of COVID-19.

Scores for proportion of the elderly people was dropped, and the remaining 10 SVSs were subjected to factor analysis. Kaiser-Meyer-Olkin (KMO) Measure of sampling adequacy test shows that sampling is acceptable (test value $=0.60$ ). The Bartlett's test of Sphericity results show that the correlation matrix is not an identity matrix (Chi-square $=4035.505, p=0.000$ ). This factor analysis diagnostic test shows that the dataset is adequate for factor analysis to proceed. Factor analysis grouped the 10 variables so that the correlation within groups is large and the correlation between groups is small, thus maximising variance within groups and minimising variance between groups. Using the correlation matrix of the final 10 variables as inputs for the factor analysis, a number of identified factors were chosen based on eigenvalues and cumulative proportion of explained variance by including another factor (group). After factoring the 10 representative variables using the principal component factor analysis, 4 factors were identified and together were found to explain about $77 \%$ of the variation across the SVS dataset. Based on the eigenvalues in Table 4 , it is evident that the 4 factors met the Kaiser criterion (Eigenvalue $\geq 1$ ) for retaining factors.

Eight of the variables showed high loading into the four factors (i.e. absolute loading value $\geq 0.7$ ). Intensity of economic activity, poverty level and level of urbanisation are highly correlated with Factor 1 and, we termed this the socio-economic condition. Population density and Road density scores loaded highly on Factor 2 and this was termed the population-accessibility condition. Factor 3 has only score of access to improved sanitation facilities and potable water loading highly on it; thus we termed it as deprivation level. Only proximity to seaports loaded highly on Factor 4. However, proximity to airports also showed a moderate loading into this factor. Factor 4 was termed ports' proximity. In summary, there are four dimensions within the subset of variables collated for this study. 


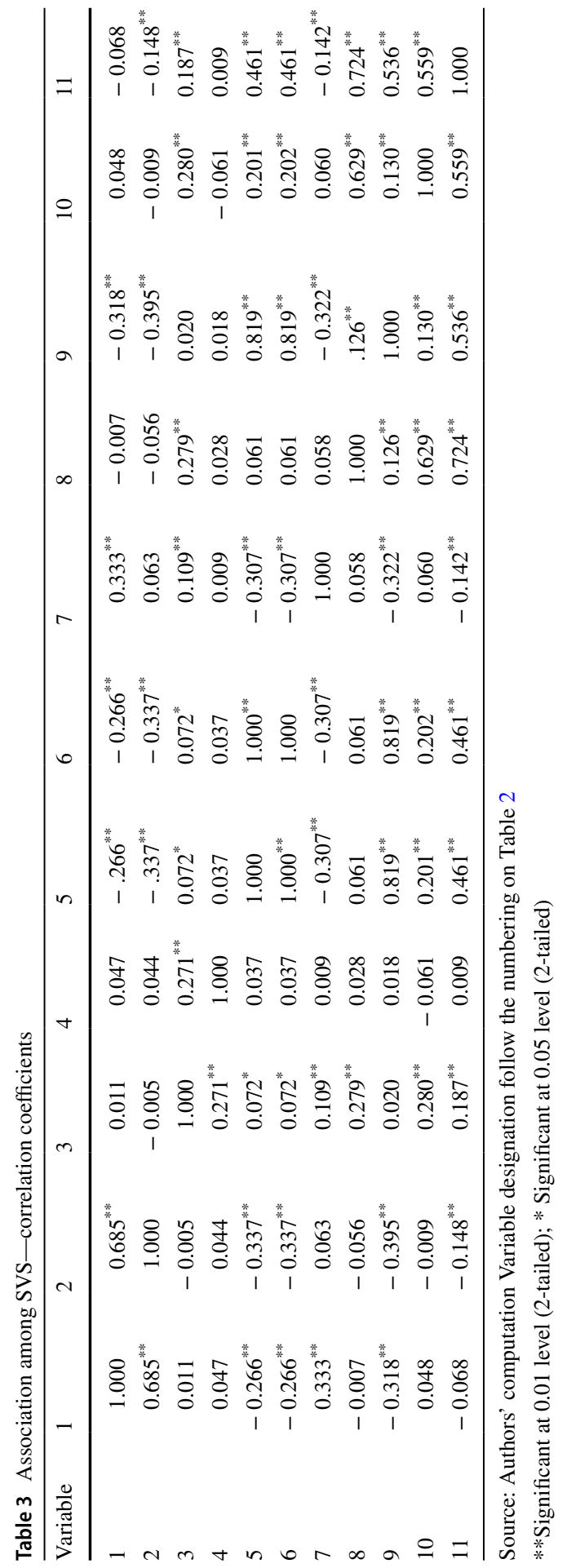


Table 4 Result of factor analysis for selected variables

\begin{tabular}{|c|c|c|c|c|}
\hline \multirow[t]{2}{*}{ Statistics } & \multicolumn{4}{|l|}{ Factors } \\
\hline & 1 & 2 & 3 & 4 \\
\hline Eigenvalues & 2.867 & 2.157 & 1.597 & 1.085 \\
\hline Cumulative variances (explained) & 28.667 & 50.234 & 66.208 & 77.059 \\
\hline Variables & \multicolumn{4}{|c|}{ Rotated factor loading } \\
\hline Score for access to improved sanitation & -0.082 & 0.035 & 0.970 & 0.034 \\
\hline Score for access to potable water & -0.102 & -0.01 & 0.965 & 0.031 \\
\hline Score for proximity to airports & 0.017 & 0.442 & 0.025 & 0.616 \\
\hline Score for proximity to seaports & 0.006 & -0.068 & 0.040 & 0.902 \\
\hline Score for intensity of economic activity & 0.917 & 0.072 & -0.038 & 0.036 \\
\hline Score for number of health care facilities & -0.516 & 0.219 & 0.114 & 0.001 \\
\hline Score for population density & -0.035 & 0.879 & -0.007 & 0.056 \\
\hline Score for poverty level & 0.937 & 0.111 & -0.051 & -0.017 \\
\hline Score for road density (accessibility) & 0.033 & 0.876 & 0.037 & 0.072 \\
\hline Score for level of urbanisation & 0.665 & 0.592 & -0.039 & 0.020 \\
\hline
\end{tabular}

Source: Authors' computation
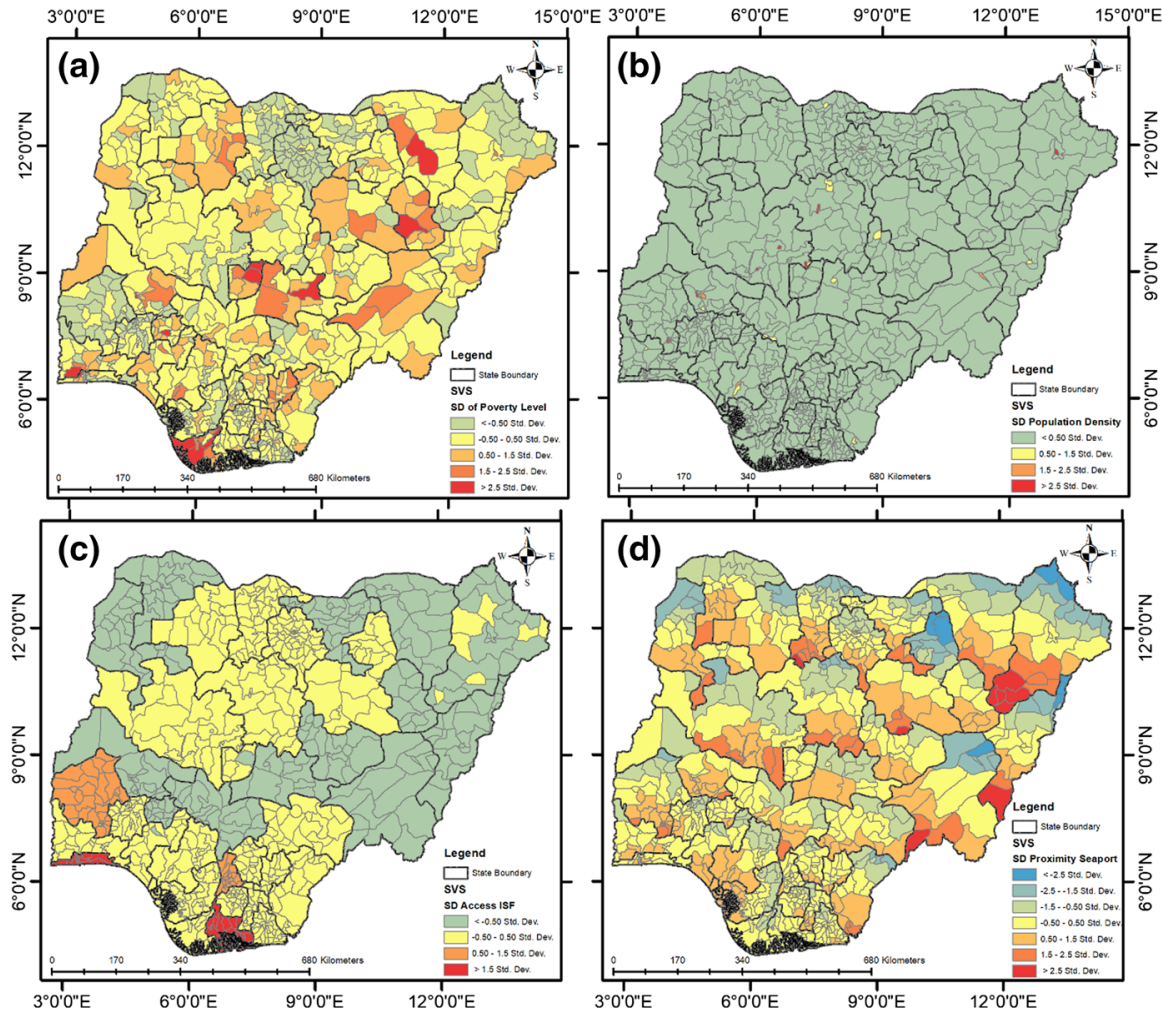

Fig. 4 Distribution of SVS values for the four factors 
The distribution of the highest loading variable for each of the four factors are presented in Fig. 4. For Factor 1, represented by the poverty levels, there are wide variations across the country as indicated in Fig. 4a. Population density represents the degree of population concentration and from Fig. 4b, the major cities are usually well above national average in this regard. Figure 4c (Factor 3) shows variations in access to improved sanitation facilities across the country., With respect to Factor 4, represented by proximity to seaports, there are noticeable variations in that regard. Essentially, LGAs on the southern part of Nigeria particularly along a few sections of the coast line have higher values than their northern counterparts.

\section{Pattern of social vulnerability index}

With the SVS computed for each of the factors selected, SoVI (Fig. 5) was computed by summing all the SVS. A weighted approach would have been adopted, but the weight of such could differ significantly from place to place. We, therefore, decided to use the equal weight approach.

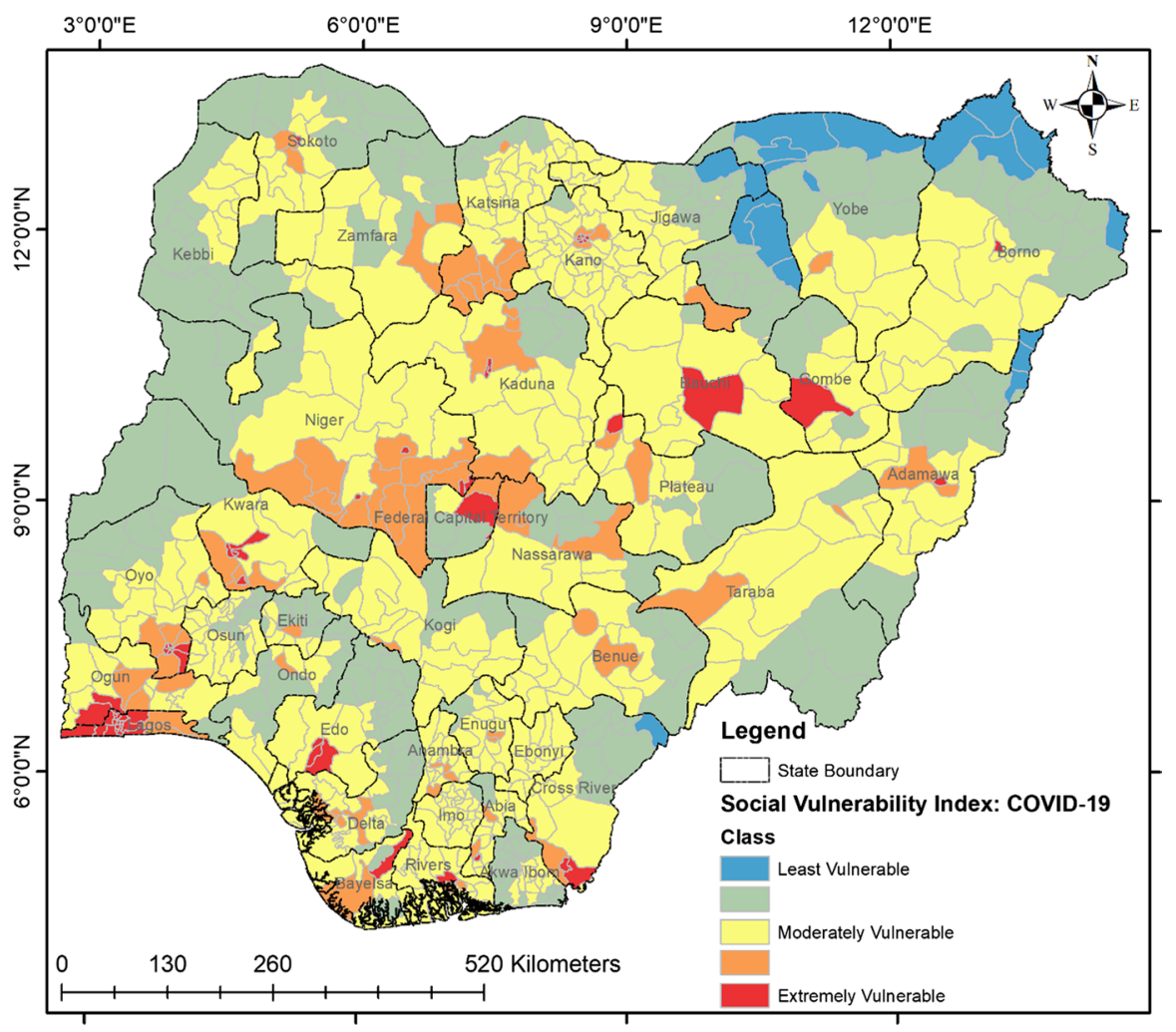

Fig. 5 Place-based social vulnerability Index for LGAs 
To determine the weight to assign is also complicated. This is because the pandemic is different from those witnessed in recent times. More so, it has been shown that vulnerability and resilience are socially constructed (Béné et al. 2016). There is also divergence on whether social vulnerability is hazard specific or a general characteristic of a social system. This then makes the weighting and approach complicated. In our case, we applied the simplest approach, equal weight and hazard-specific approach. This is because there is no clear evidence on appropriate weighting relevant for this current pandemic.

The result (Fig. 6), highlight areas with below and above average vulnerability index values. The minimum SoVI values is 2.3 (least vulnerable) and the maximum value recorded is 6.8 (extremely vulnerable). A mean of $3.31(\mathrm{SD} \pm 0.42)$ was recorded and the distribution was positively skewed. The LGAs classified as moderately vulnerable (Group 3$)$ are about 55\% $(n=426)$ of the LGAs. About 8\% $(n=62)$ of the LGAs falls within the extremely vulnerable group. The five most extremely vulnerable LGAs are Abuja Municipal (6.8), Ilorin West (5.6), Ibadan South-East (5.0), Alimosho (5.0), and Jos North (4.9) while the least vulnerable LGAs are Abadam (2.3), Guri, Kala/Balge, Zaki, Kukawa (2.5).

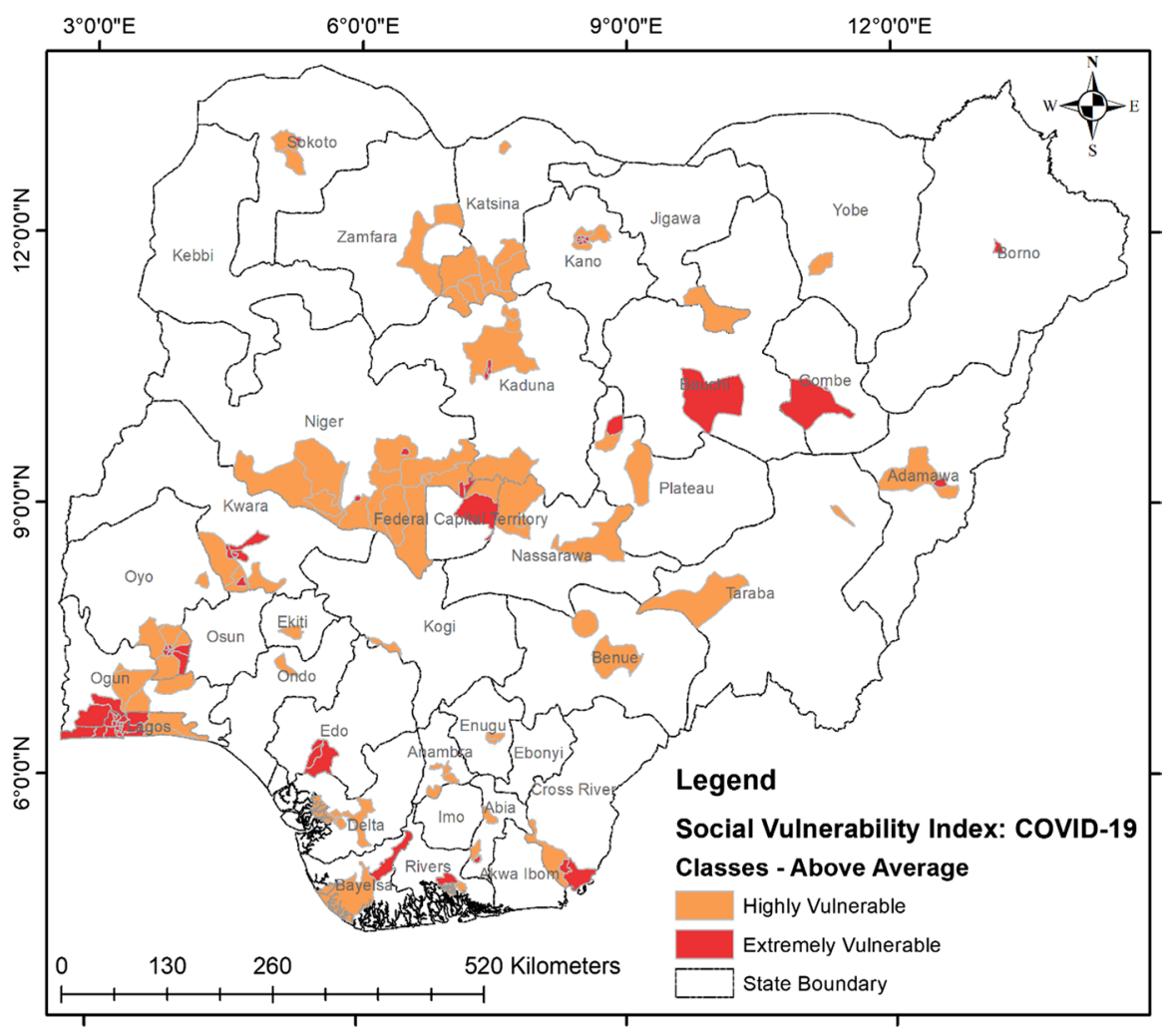

Fig. 6 Location of LGAs with above-average SoVI values 
Using the UN Adjusted total population estimates for 2020, around $21 \%$ of the Nigerian population could be found around LGAs with below average vulnerability. Majority of the population (48\%) can be found in LGAs that are moderately vulnerable. Beyond the moderately vulnerable class, $32 \%$ of the populace are residing within the LGAs classified as highly vulnerable which is roughly 63 million people, and these are mostly in the urbanised LGAs of the country.

\section{Comparison of SoVI with COVID-19 incidence in Nigeria}

In order to test the validity of the SOVI index developed, we examined the explanatory power of the SoVI computed (descriptive statistics at the State level) with case attributes at the State level using the April 15 data from the NCDC website (https:// covid19.ncdc.gov.ng/).

Bayesian correlation analysis was carried out to ascertain the association between cases and SoVI distribution among the 20 States for which there were confirmed cases as at the time of this study. This technique was adopted since it can test the degree of belief in the presence of linear association between the variables of interest. Using the Zellner-Siow's approach for computing the Bayes Factor, the Bayesian analysis was carried out by comparing the marginal likelihoods between a null and the alternative hypothesis. The results (Table 5) showed that there is a linear association between SoVI and case attributes. For Mean SoVI against the number of confirmed cases of COVID19 across the States the estimated correlation coefficient is high $(r=0.812)$ with a corresponding Bayes factor of 0.001 . This indicated that there is significant evidence of a linear and positive relationship. Similar deductions were also made for Mean SoVI versus Active Cases; Discharged cases and Deaths based on the correlation coefficient and the Bayes Factors. For the minimum, maximum, range and standard deviation of SoVI against the COVID-19 case attributes, there is moderate evidence (Bayes factor of 2.423-4.091) in favour of null hypothesis - no linear relationship between the pairs.

Table 5 Bayes factor inference on pairwise correlation

\begin{tabular}{lllllll}
\hline Case attributes & & & Confirmed & Active & Discharged & Deaths \\
\hline SoVI distribution & \multirow{2}{*}{ Mean } & Correlation coefficient & 0.812 & 0.798 & 0.825 & 0.809 \\
& \multirow{2}{*}{ Min } & Bayes factor & 0.001 & 0.001 & 0.000 & 0.001 \\
& \multirow{4}{*}{ Max } & Correlation coefficient & 0.307 & 0.305 & 0.304 & 0.334 \\
& & Bayes factor & 2.475 & 2.499 & 2.523 & 2.091 \\
& \multirow{2}{*}{ Range } & Correlation coefficient & 0.31 & 0.308 & 0.308 & 0.311 \\
& & Bayes factor & 2.437 & 2.455 & 2.464 & 2.423 \\
& \multirow{2}{*}{ SD } & Correlation coefficient & 0.23 & 0.229 & 0.229 & 0.225 \\
& & Bayes factor & 3.652 & 3.665 & 3.669 & 3.725 \\
& & Correlation coefficient & 0.219 & 0.201 & 0.241 & 0.256 \\
& Bayes factor & 3.822 & 4.091 & 3.473 & 3.24 \\
\hline
\end{tabular}

Bayes Factor: Null versus alternative Hypothesis

$N=20$ 
Consequently, the SoVI index for COVID-19 as modelled in this study captures the social vulnerability of the states to COVID-19.

\section{Discussion}

According to Flanagan et al. (2018), social vulnerability mapping and quantification can be applied to a variety of hazards, threats, and social or health outcomes. Thus, its investment in its development is a worthwhile venture. The results of the index computation reveal disparities in the level of social vulnerability to COVID-19 across the country. The extremely vulnerable places lie in the some of the most urbanised LGAs of the country. This puts states such as Lagos, Kwara, the Federal Capital Territory, Oyo, Plateau at great risk of COVID-19 infection. Our finding to some extent aligns with some earlier observations of the Presidential Task Force on COVID-19 (PTFCOVID) on distribution of COVID-19 infection in the country. It announced much later that " $[t]$ he majority of the confirmed cases are in a handful of local government areas in the country as 20 out of the 774 LGAs nationwide account for 60 per cent of the cases" (Oyeleke 2020). Some of these 20 high burden LGAs include Abuja Municipal, Alimosho (Oyeleke 2020). This observation as matter of fact made the Federal Government of Nigeria at some point consider precision lockdown on these hotspots. The observed variation at the state level for the SoVI gives an indication of how social vulnerability factors varies among the states in Nigeria, thus alluding to the fact that outcomes are a reflection of a combination of predisposing and protective conditions or factors.

The preliminary test of the association between COVID-19 cases and SoVI values showed that there is a linear and positive relationship. This is in agreement with existing literature on established and re-emerging diseases and emerging literature on COVID-19. Findings have shown that in the aftermath of Hurricane Katrina, communities with high population of vulnerable people are likely to recover slower even without heavy damages and even slower to recover are those with heavy damage and with highly vulnerable population (Flanagan et al. 2011). While examining the association between social vulnerability and the Ebola Virus in Liberia, Stanturf et al. (2015) showed that some of the counties with highest level of social vulnerability recorded the highest level of Ebola Virus disease infection. In the United States of America, Ratnapradipa et al. (2017) tested the predictive power of SoVI in explaining the rates of occurrence of Lyme disease in relation to social vulnerability. The study showed that the model performed differently for different regions (fairly better for Middle Atlantic zone of the North-eastern region and South Atlantic zone of the Southern region) in the US. Similar observations were noticed in the association between COVID-19 infection rates and social vulnerability in the United States of America (Karaye and Horney 2020; Dasgupta et al 2020; Neelon et al 2021).

\section{Limitations}

However, there are some limitations which are largely associated with the dearth of granular level data. For instance, data on confirmed cases, recoveries and mortalities 
at the LGA level are not publicly available. What is currently and publicly available and accessible is data aggregated at the state level. Unfortunately, this is not just limited to COVID-19 data; it was the same for some population, transport, household and socioeconomic variables such as urban population, poverty, road density and GDP. Secondly, the lack of access of COVID-19 infection data at the LGA level limited our ability to test the efficacy of the SoVI index at a finer geographic scale. Lastly, the data on COVID-19 infection and fatality, as we are fully aware is time sensitive. In light of this, its geographical distribution has significantly changed since the research was conducted.

\section{Conclusion}

Clearly, the paper developed a place-based SoVI to COVID-19 index for Nigeria where the number of cases is increasing exponentially, and where a variety of recommended and adopted measures have limited effectiveness. No doubt, understanding where the vulnerability hotspots are could help in the implementation of mitigation measures such as the current vaccination campaign measures. The current exercise has shown that showed that most of the states in the country are socially vulnerable to COVID-19 and therefore effective preventive and disease control measures should be implemented so as to minimise the spread and impact of COVID-19. Nevertheless, the visual representation of the place-based vulnerability to COVID-19 index should guide and direct the Federal and State Ministries of Health, NCDC and other relevant first responders to these areas so as to contain any possible spread especially in the allocation of healthcare personnel, emergency medical services, vaccines, equipment and palliatives for the vulnerable population.

Funding No funding was provided for this study.

Data availability Data are available upon request.

\section{Declarations}

Conflict of interest The authors have none to declare.

Ethical approval The study did not require ethical approval because it mainly relied on anonymized secondary data.

Ethical standards The study has complied with ethical standards.

Informed consent The study did not require ethical approval because it mainly relied on anonymized secondary data. 


\section{References}

Béné C, Al-Hassan RM, Amarasinghe O, Fong P, Ocran J, Onumah E, Ratuniata R, Tuyen TV, McGregor JA, Mills DJ (2016) Is resilience socially constructed? Empirical evidence from Fiji, Ghana, Sri Lanka, and Vietnam. Global Environ Chang 38:153-170

Central Intelligence Agency (2015) Nigeria: The World Factbook. CIA, Fairfax, Virginia. https://www. cia.gov/library/publications/the-world-factbook/geos/ni.html. Accessed 8 Nov 2015.

Cutter SL (1996) Vulnerability to environmental hazards. Prog Hum Geogr 20(4):529-539

Dasgupta S, Bowen VB, Leidner A, Fletcher K, Musial T, Rose C, Cha A, Kang G, Dirlikov E, Pevzner E, Rose D (2020) Association between social vulnerability and a county's risk for becoming a COVID-19 hotspot-United States, June 1-July 25. Morb Mortal Wkly Rep 69(42):1535

ESRI (2019) World Port Index. In: ESRI Germany (ed) World Port Index 26th Edition ed. ArcGIS Online.

ESRI (2020) World Airports. In: ESRI (ed). Redmond. ArcGIS Online.

Flanagan BE, Gregory EW, Hallisey EJ, Heitgerd JL, Lewis B (2011) A social vulnerability index for disaster management. J Homeland Secur Emerg Manag 8(1)

Flanagan BE, Hallisey EJ, Erica Adams M, Lavery A (2018) Measuring community vulnerability to natural and anthropogenic hazards: the Centers for Disease Control and Prevention's Social Vulnerability Index. J Environ Health 80(10):34-36

Karaye IM, Horney JA (2020) The impact of social vulnerability on COVID-19 in the US: an analysis of spatially varying relationships. Am J Prev Med 59(3):317-325

Lawal O, Arokoyu SB (2015) Modelling social vulnerability in sub-Saharan West Africa using a geographical information system. Jàmbá: Journal of Disaster Risk Studies 7(1):11

Lawal O, Arokoyu SB (2019) Analysis of geographic hierarchy from attributes of local government area in Nigeria. Forum Geografic XVII I(1):83-92

Manyena B (2016) After Sendai: is Africa bouncing back or bouncing forward from disasters? Int J Disaster Risk Sci 7(1):41-53

National Population Commission (2010) 2006 population and housing census of the federal republic of Nigeria: priority table (LGA). In: NPC (ed) Housing characteristics and amenities tables. NPC, Abuja

Neelon B, Mutiso F, Mueller NT, Pearce JL, Benjamin-Neelon SE (2021) Spatial and temporal trends in social vulnerability and COVID-19 incidence and death rates in the United States. PLoS ONE 16(3):e0248702

Nigeria MDG Information System (2015) Health facilities in Nigeria. In: NMIS (ed) 1 ed. openAFRICA, Abuja

Okafor SI, Osayomi T (2021) Geographical dynamics of COVID-19 in Nigeria. In: Akhtar R (ed) Coronavirus (COVID-19) outbreaks, environment and human behaviour: international case studies. Springer, Switzerland

Olusola A, Olusola B, Onafeso O, Ajiola F, Adelabu S (2020) Early geography of the coronavirus disease outbreak in Nigeria. Geo J. https://doi.org/10.1007/s10708-020-10278-1

Onafeso OD, Onafeso TE, Olumuyiwa-Oluwabiyi GT, Faniyi MO, Olusola AO, Dina AO, Hassan AM, Folorunso SO, Adelabu S, Adagbasa E (2021) Geographical trend analysis of COVID-19 pandemic onset in Africa. Soc Sci Humanit Open 4(1):100137

Osayomi T, Adeleke R, Taiwo OJ, Gbadegesin AS, Fatayo OC, Akpoterai LE, Ayanda TJ, Moyin-Jesu J, Isioye A (2021a) Cross-national variations in COVID-19 outbreak in West Africa: where does Nigeria stand in the pandemic? Spat Inf Res 29:535-543. https://doi.org/10.1007/s41324-020-00371-5

Osayomi T, Adeleke R, Akpoterai LE, Fatayo OC, Ayanda JT, Moyin-Jesu J, Isioye A, Popoola AA (2021b) A Geographical analysis of the African COVID-19 paradox: Putting the Povertyas-a-Vaccine Hypothesis to the test. Earth Syst Environ 5:799-810. https://doi.org/10.1007/ s41748-021-00234-5

Oyeleke S (2020) Full list: 20 LGs account for 60\% COVID-19 cases in Nigeria-PTF https://punchng. com/20-lgs-account-for-60-covid-19-cases-in-nigeria-ptf/. Accessed 10 Sep 2021

Population Reference Bureau (2021) 2021 World Population Data Sheet. Washington, Population Reference Bureau

Ran J, MacGillivray BH, Gong Y, Hales TC (2020) The application of frameworks for measuring social vulnerability and resilience to geophysical hazards within developing countries: a systematic review and narrative synthesis. Sci Total Environ 711:134486 
Ratnapradipa D, McDaniel JT, Barger A (2017) Social vulnerability and Lyme disease incidence: a regional analysis of the United States, 2000-2014. Epidemiol Biostat Public Health 14(2)

Stanturf JA, Goodrick SL, Warren ML Jr, Charnley S, Stegall CM (2015) Social vulnerability and Ebola virus disease in rural Liberia. PLoS ONE 10(9):e0137208-e0137208

Tatem AJ, Gething PW, Bhatt S, Weiss D, Pezzulo C (2013) Pilot high resolution poverty maps. In: Southampton/Oxford UO (ed). School of Geography and Environmental Science, University of Southampton, Southamptom

The World Bank Group (2015) Nigeria. World Bank, Washington, DC. http://www.worldbank.org/en/ country/nigeria/overview. Accessed 9 Dec 2016.

The World Bank Group (2016a) Annual population growth rate. In: Group TWB (ed). The World Bank Group, New York

The World Bank Group (2016b) World bank development indicators: Nigeria. In: Group TWB.(ed). The World Bank Group, New York.

United Nations (2020) Progress towards the Sustainable Development Goals: report of the Secretary General. United Nations Social and Economic Council

WorldPop (2014) Nigeria 100m age structures. Alpha version 2014 estimates of number of people in each 5 -year age group per grid square, with national totals adjusted to match UN population division estimates. In: School of geography and environmental science - University of Southampton (ed). School of Geography and Environmental Science - University of Southampton, Southamptom

WorldPop (2020) Estimated total number of people per grid-cell: Nigeria 2019. In: School of Geography and Environmental Science - University of Southampton (ed). School of Geography and Environmental Science - University of Southampton, Southamptom 